\title{
Practical Application of In-door Tested Scaled Models on Real Building structures
}

\author{
Irshad Ullah, MNR Baharom, H.Ahmad, H.M.Luqman, Zainab Zainal
}

University Tun Hussien Onn Malaysia, Batu Pahat Johor, 86400 Malaysia

\begin{tabular}{ll}
\hline \hline Article Info & ABSTRACT \\
\cline { 3 - 3 } Article history: & $\begin{array}{l}\text { Lightning indoor testing got a very low attention of the researchers. Although } \\
\text { lightning is impossible to create inside the laboratory however it can be } \\
\text { presented using high voltage impulse. High voltage impulse was generated in } \\
\text { theceived Feb 11,2018 } \\
\text { Revised Apr 2, 2018 } \\
\text { Accepted Apr 27, 2018 }\end{array} \quad \begin{array}{l}\text { were tested under the high voltage condition. This idea was implemented } \\
\text { practically by applying it on different real building structures. Different } \\
\text { building with different roof tops were observed practically and it was found } \\
\text { that this research work has a good agreement of the lightning strike points } \\
\text { observe during the indoor activities in high voltage lab and out door activity } \\
\text { during the field study. }\end{array}$ \\
$\begin{array}{ll}\text { Lightning flash } \\
\text { Geometrical shapes }\end{array}$ Air terminal &
\end{tabular}

Copyright @ 2018 Institute of Advanced Engineering and Science. All rights reserved.

\section{Corresponding Author:}

Irshad Ullah,

University Tun Hussien Onn Malaysia

Batu Pahat Johor, 86400 Malysia.

Email: irshadullah95@yahoo.com

\section{INTRODUCTION}

Lightning protection system consists of Lightning Air Terminal (LAT), ground conductor and earth wire. Different standards use the convention method of lightning protection in which LAT attract lightning and diffuses it to the ground. Lightning can cause damge to the building structrue and huma as well as the equipment [1]. Different standards are used for the lightning protection system installation and provide all the information about building protection [2], [3].

Every year number of people are killed due to lightning in different part of the world. Malaysia is one of the high flash density countries and therefor many people get struck due to lightning [4].

This paper presents the effect of lightning on the installed air terminals during the indoor and real observation during field work.

\section{LIGHTNING ATTACHMENT TO STRUCTRUES}

When a direct lightning approaches the building structure it effect the surface of a building structrue and produce high electric field on the roof top of the building structure. Similarly the height of the building, its width and legth also play key role in lightning attraction. The rod is also the key to attract lightning and protect the building structures [5], [6]. Lightning flash can be attracted by the LATs installed on the building structures with a different ratio. The placement of the LAT plays an important rule in lightning attraction. However, the LATs installed on the corners has much efficiency as compare to the LAT installed in the middle of th building roof top [7]. The placement of LAT is very important on any building structure. Due to correct placement of LAT on the building structure it can attract the lightning flashes and can protect the building structures [8]. 


\section{PROPOSED PROCEDURE}

Indoor testing of the different geometrical structures was carried out insid the high voltage laboratory. High voltage impulse generator was used to produce the flashover for the scaled objects. The building wer scaled down by considering the ratio for a single story building in accordance with the [9]. The scaled objects were tested using high voltage impulse genertro as shown in Figure 1.

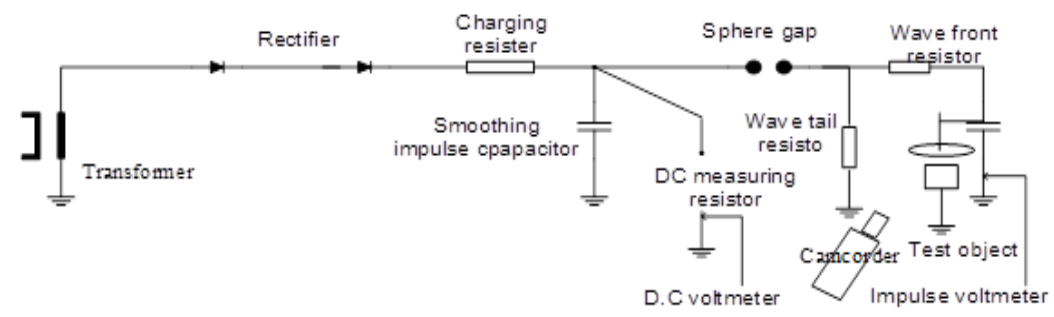

Figure 1. Schematic diagram of impulse generator

Height of the building was kept as $10 \mathrm{~cm}$ for each shpe and impulse voltage was applied. The strike points on different shapes were observe and the field work was carrid out by observing the roof tops of different building structures.

\section{RESULTS}

During the experimental process the impulse votage was applied on the flat roof top and all the installe Lighning Air Terminals (LATs) were struck by lightning on the corner. The flashover on different air terminal of the flat roof is given in Figure 2.

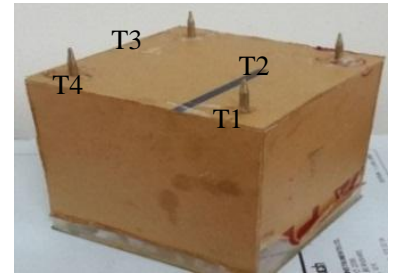

(a)

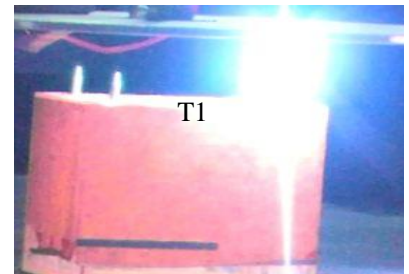

(b)

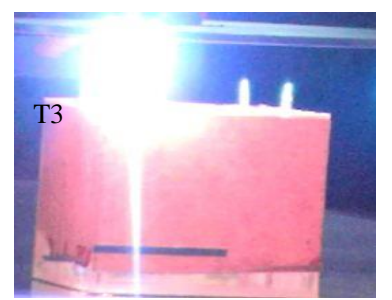

(d)

(c)

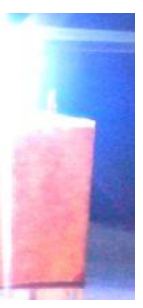

(e)

Figure 2. Flashover on the flat roof top 
Similary during the field observation it was foud that the building structure were also struck by lightning on the corners. Faber towers wer visited by the reseachers and the strike pattern was found which has a good agreement with the experimental work done in the high voltage laboratory. Figure 3 show the strike pattern on real building of Faber Towers.

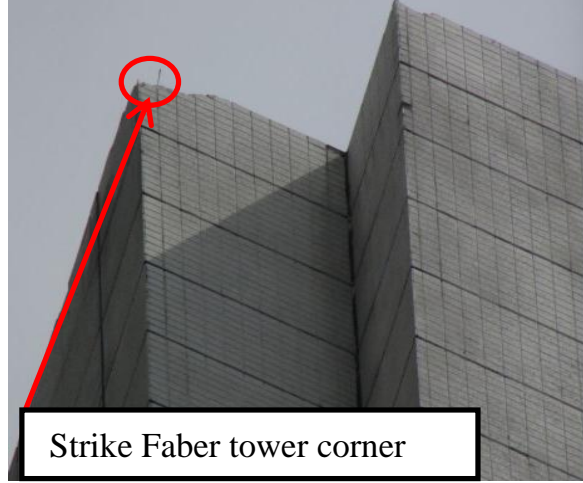

(a)

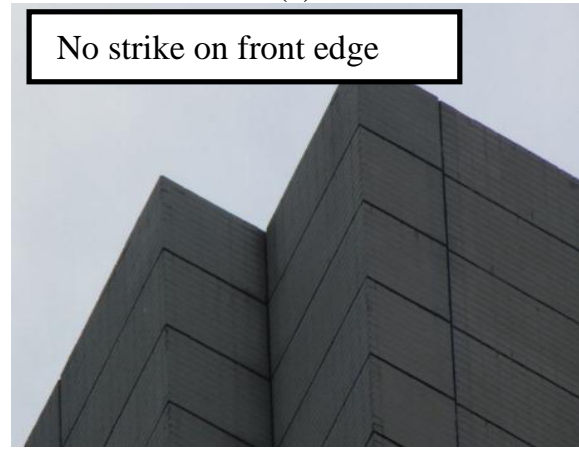

(c)

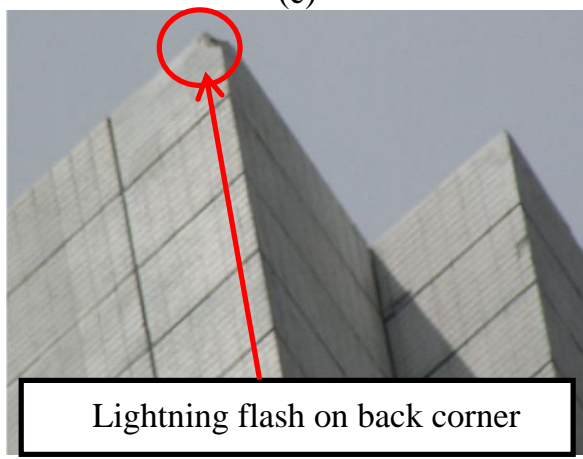

(e)

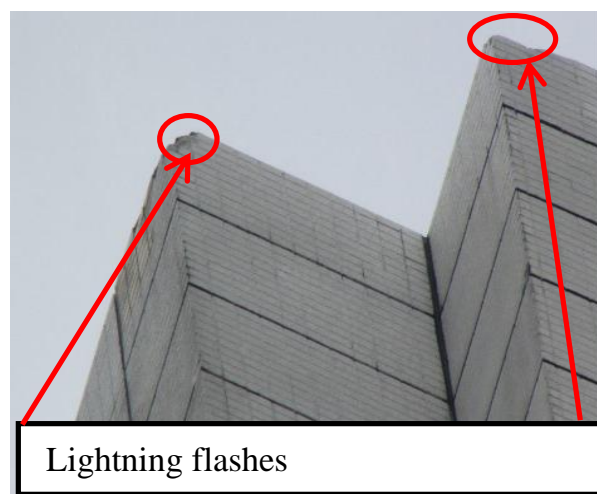

(b)

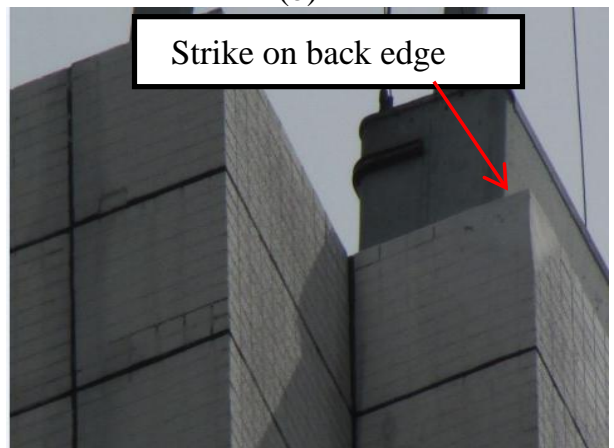

(d)

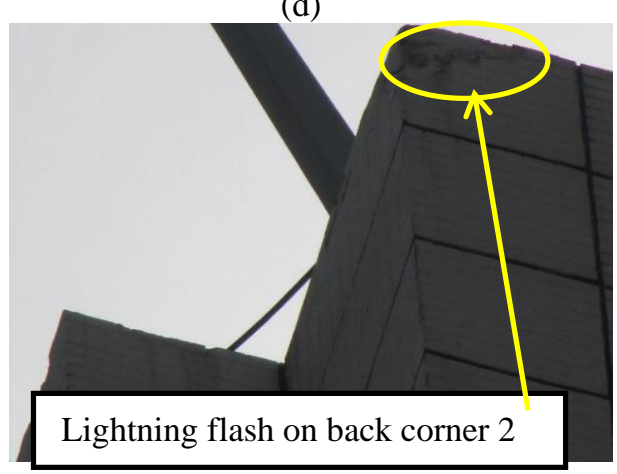

(f)

Figure 3. Lightning strike points on Faber towers

Figure 3 indicates that all the lightning flashes were struck on the corner of the real building roof top. Therefore, the idoor lightning testing can be applied to the given building installed with LAT and it can be protected from the lighting strikes.

Gable shape was also tested in high voltage laboratory which is shown in Figure 4 different air terminal is given in Figure 2. 

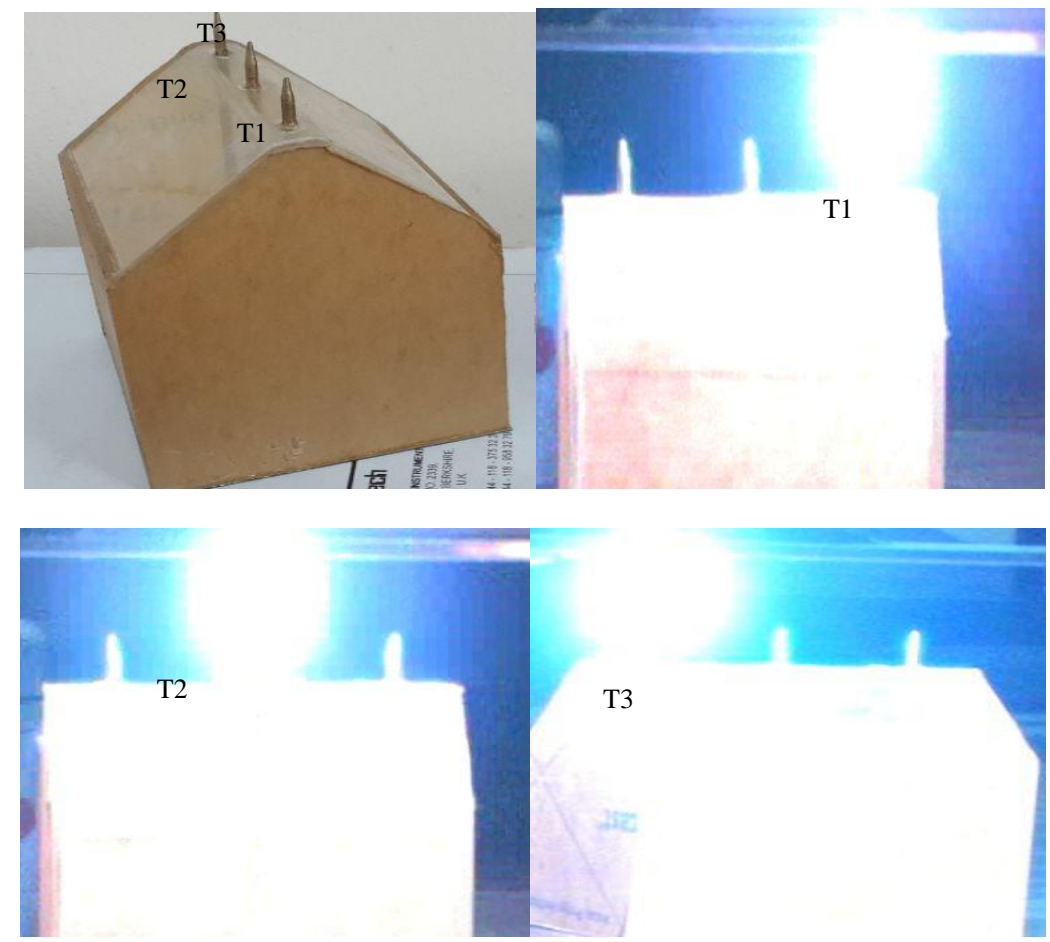

Figure 4. Flashover on Gabel shape

For the Figure 4 it can be seen all the flashes are attracted by the installed air terminals. During the field observation the incubator 1 Putrajay was visited and the lighning strike points were found on the arc roof top.

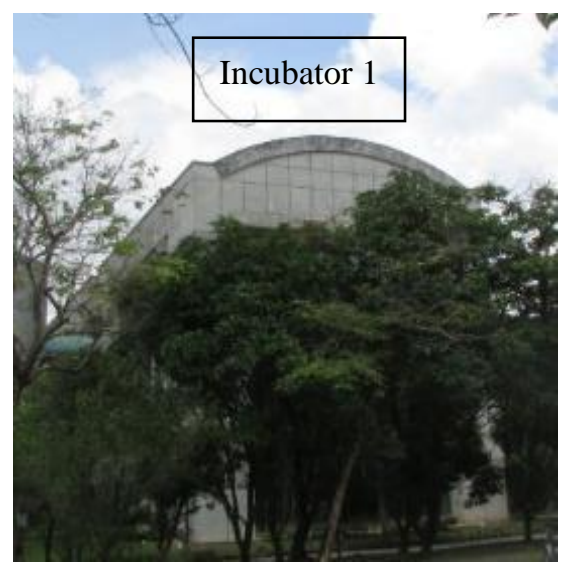

(a)

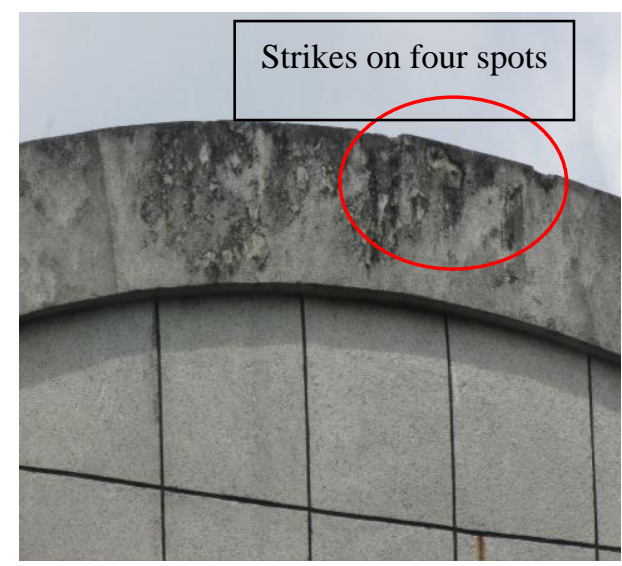

(b)

Figure 5. Strikes on the incubator 1

From the Figure 5 it can be found that the gable shape tested in indoor testing can be impelemented on the building structreu like incubatore 1 Putrajaya.

Similarly UTH library was also taken as a case study. UTHM Library is one of the heighes building and it is exposed to lightning and has the probability to be struck be lightning. Fro the libray a cylindrical model was tested which can be implemented on UTHM Library. Llightning distribution on the given shape. 


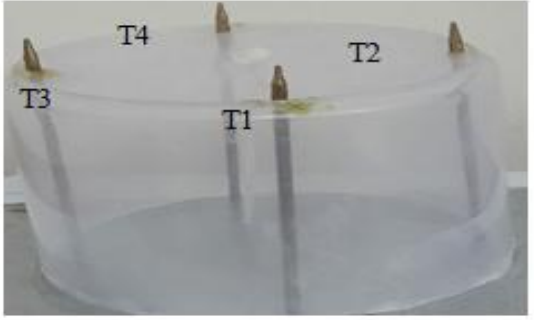

(a)

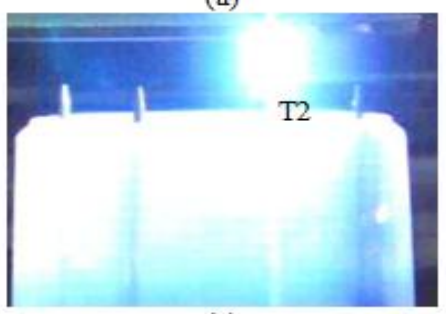

(c)

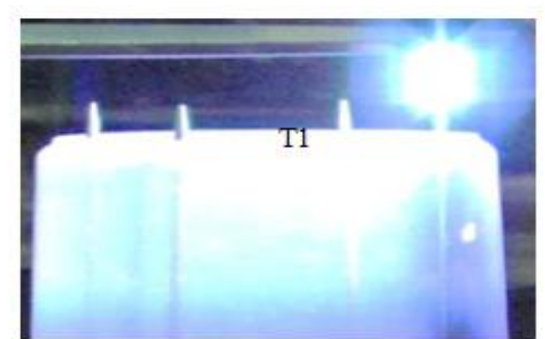

(b)

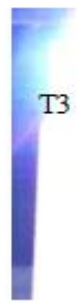

T3

(d)

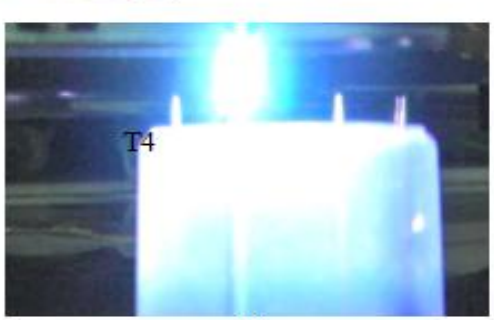

(e)

Figure 6. Cylindrical shape with flashover

The given testing can be used for UTHM Libray which is given in Figure 7. From the tested model it can be implemented for the library as it has cylindrical shape.

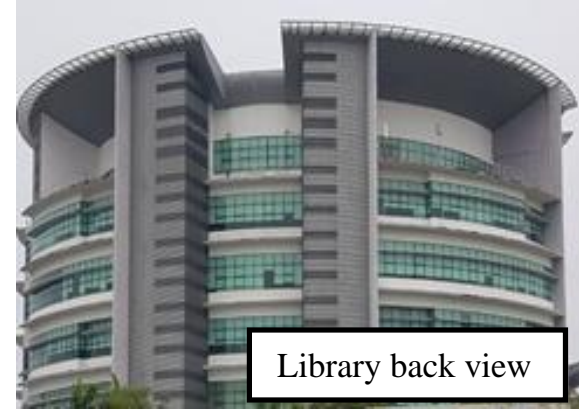

(a)

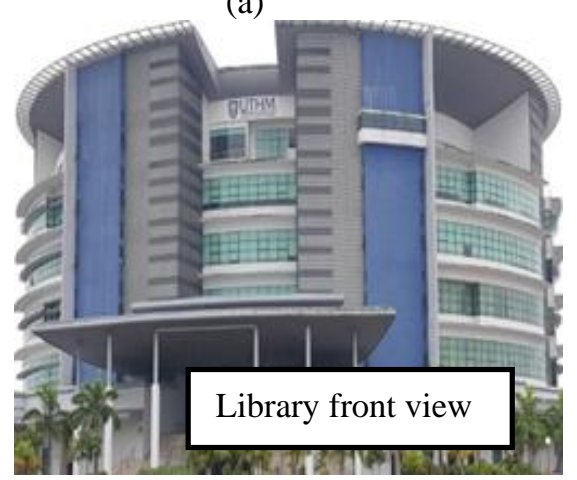

(c)

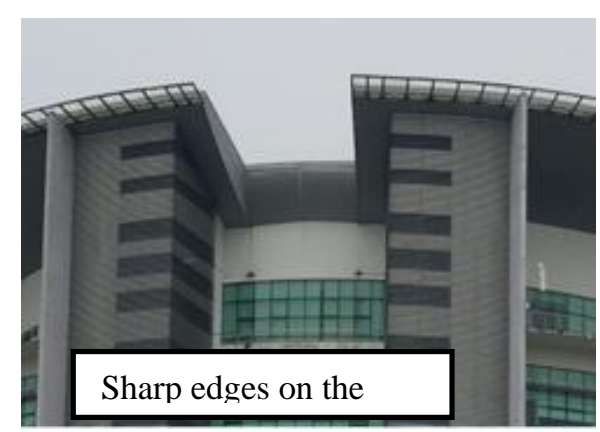

(b)

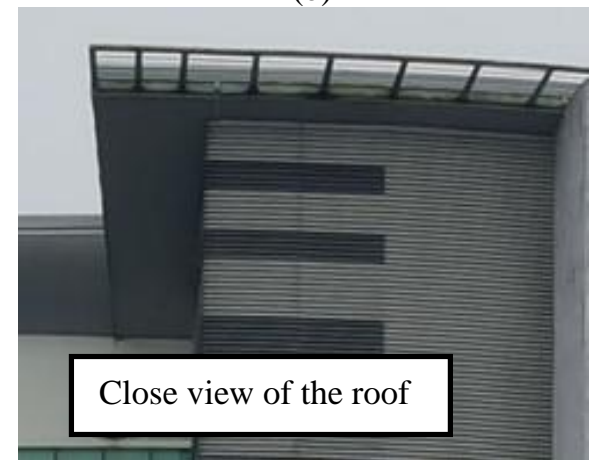

(d)

Figure 6. UTHM Libray 


\section{CONCLUSION}

The implementation of an indoor testing has been carried out and the different geometrical structures were selected. The shapes were tested inside the high voltage laboratory. The field observation was taken in accordance with the same shapes tested in the lab. During the field observation it was found that the geometrical shapes in real has the same charactersitics of lightning attachement. Therefore, the tested model can be applied for the practical application on the observed building structures as well asl the other building structures.

\section{ACKNOWLEDGMENT}

The author would like to thank the Faculty of Electrical and Electronics Engineering University Tun Hussein Onn Malaysia (UTHM) for being a part of this research and providing all the facilities for experimental work. Special thanks to Oricc UTHM which supports this research uder the Grant Contract havin Vote No. U563.

\section{REFERENCES}

[1] R. L. Holle, "Some Aspects of Global Lightning Impacts, " in ilternationional conference on lighnting protection system (ICLP), 2014, pp. 1390-1395.

[2] BS EN / IEC 62305 Lightning protection standard, vol. 44, no. 0. 2008, pp. 1-107.

[3] "NFPA Standard for the Istallation Lightning Protection System," 2006.

[4] Z. a. Baharudin, N. A. Ahmad, J. S. Mäkelä, M. Fernando, and V. Cooray, "Negative cloud-to-ground lightning flashes in Malaysia," J. Atmos. Solar-Terrestrial Phys., vol. 108, pp. 61-67, Feb. 2014.

[5] F. D'Alessandro, "Striking distance factors and practical lightning rod installations: a quantitative study," $J$. Electrostat., vol. 59, no. 1, pp. 25-41, Jul. 2003.

[6] F. D'Alessandro, “On the optimum rod geometry for practical lightning protection systems," J. Electrostat., vol. 65, no. 2, pp. 113-121, Feb. 2007.

[7] A. Kern and M. Mathieu, "Probability of lightning strikes to air-terminations of structures using the electrogeometrical model theory and the statistics of lightning current parameters," in International Conference on Lightning Protection (ICLP), 2010, vol. 2010, pp. 1-8.

[8] A. Srivastava and M. Mishra, "Positioning of lightning rods using Monte Carlo technique," J. Electrostat., vol. 76, no. 3, pp. 201-207, Aug. 2015.

[9] V. Heller, "Scale effects in physical hydraulic engineering models," J. Hydraul. Res., vol. 49, no. 3, pp. 293-306, Jun. 2011. 